\title{
O CONCEITO CONSTITUCIONAL DE ASSISTÊNCIA SOCIAL À LUZ DOS DIREITOS FUNDAMENTAIS E A INTERPRETAÇÃO SISTEMÁTICA NA DECISÃO DA LIMINAR CONCEDIDA NA ADIN 2.028
}

\author{
THE CONSTITUTIONAL CONCEPT OF SOCIAL \\ ASSISTANCE IN LIGHT OF FUNDAMENTAL RIGHTS AND \\ SYSTEMATIC INTERPRETATION IN THE PRELIMINARY \\ INJUNCTION GRANTED ON CASE ADIN 2.028 \\ (BRAZILIAN SUPREME FEDERAL COURT)
}

\author{
FABIO ADRIANO STÜRMER KINSEL ${ }^{1}$
}

\begin{abstract}
RESUMO: A Constituição Federal de 1988, que foi resultado de vontades e anseios reprimidos em mais de vinte anos de regime autoritário, atribuiu ao Estado o dever de prover direitos sociais. Porém, o Estado não tem condições de prover muitos destes direitos e desde muito tempo antes da Constituição Federal de 1988 se vale da colaboração de entidades privadas que atuam na saúde, educação e assistência social latu sensu de forma desinteressada. Embora estejam alcançando à população alguns direitos sociais, estas entidades são também sujeitos de direitos individuais previstos no artigo $5^{\circ}$ da Constituição Federal, especialmente no parágrafo segundo deste artigo. Em reconhecimento das atividades destas entidades que atuam no país desde antes da Proclamação da República, e cuja legislação já previa desoneração tributária há décadas, em 1988 o Legislador Constituinte erigiu à imunidade $a$ isenção de contribuições destinadas à seguridade social. A imunidade é um instituto brasileiro. Não há notícia de que outro país tenha adotado cláusula de desoneração expressa em texto constitucional. A prática conhecida é que desonerações fiscais sejam feitas por meio de isenções. Ocorre que o legislador infraconstitucional trata a imunidade como se mera isenção o fosse: restringe as atividades passíveis de serem reconhecidas como de beneficência social, em franco desrespeito ao Supremo Tribunal Federal, o qual, ao referendar a medida liminar deferida na Ação Direta de Inconstitucionalidade - ADIN - de número 2.028, interpretou a Constituição Federal de 1988 de forma sistemática e
\end{abstract}

Comentário de Jurisprudência recebido em 21.02.2014. Comentário de Jurisprudência aceito para publicação em 07.04.2014.

${ }_{1}^{1}$ Professor de Direito Tributário do Terceiro Setor (MBA). Especialista em Direito Tributário. Mestrando em Direito pela PUCRS. Membro do grupo de pesquisas em Direito Tributário da PUCRS - ênfase na tributação do terceiro setor. Membro da Escola Superior de Direito Tributário. Advogado em Porto Alegre. fabio@kinsel.com.br 
definiu o que é assistência social para os fins da imunidade às contribuições de seguridade social.

PALAVRAS-CHAVE: ADIN 2.028; Assistência Social; Imunidade; Entidade Beneficente de Assistência Social; Conceito Constitucional; Interpretação Sistemática; Imunidade; Direito Fundamental.

ABSTRACT: Resulting from 20 years of authoritarian regime the 1988 Federal Constitution entitles the Estate with the duty to provide social rights. The Estate, however, don't have the conditions to provide all of this rights. Long time before de 1988 Federal Constitution it has private collaboration of nonprofit organizations in health, education and social security systems, organizations that don't have expectations of retribution. Although these nonprofit organizations are providing some social rights to the population, these same organizations have personal rights, written on the $5^{\circ}$ article of Federal Constitution, especially in his second paragraph. In recognition of these entities activities operating in the country, since before de Republic proclamation, the historic legislation had taxes privileges to these nonprofit organizations. And in 1988 the legislator gives tax immunity to all the contributions to social welfare due by these organizations. The taxes immunity is a Brazilian creation. There is no knowledge of this constitutional principle in others constitutional texts. The main praxis is that this exoneration is made by infra constitutional regulations. The problem is that the infra constitutional legislator deals with tax immunity as if a tax exemption, with no boundaries on the constitution: narrow the activities recognized as social assistance, in disaccording with the rules of the Federal Supreme Court. This court ruled in an injunction argued on the 2.028 - Direct Action of Unconstitutionality, interpreting systematically the Federal Constitution and defining what is social assistance that deserves taxes immunity of social contributions.

KEYWORDS: ADIN 2.028; Social Assistance; Immunity; Nonprofit Organization of Social Assistance; Constitutional Concept; Systematic Interpretation; Fundamental Rights.

SUMÁRIO: 1. Os Direitos Sociais previstos no art. $6^{\circ}$ da Constituição Federal de 1988; 2. A Imunidade do Parágrafo Sétimo do artigo 195, da Constituição Federal de 1988; 3. A Imunidade como Direito e Garantia Fundamental; 4. Interpretação da Imunidade das Entidades Beneficentes de Assistência Social; 4.1 Interpretação da Imunidade das Entidades Beneficentes de Assistência Social às Contribuições de Seguridade Social dada pelo Legislador Infraconstitucional; 4.2 Intepretação da Imunidade das Entidades Beneficentes de Assistência Social às Contribuições de Seguridade Social dada pelo Supremo Tribunal Federal no Julgamento da ADIN 2.028 no que concerne ao Conceito de Assistência Social; Conclusão; Bibliografia.

SUMMARY: 1 . The Social Rights on the 6th article of the 1988 Federal Constitution; 2. The Immunity on the 195 article, paragraph 7th, of the 1988 Federal Constitution; 3. The Immunity as a Fundamental Right; 4 . The Interpretation of Immunity for Social Welfare Nonprofit Organizations; 4.1 The Interpretation of Immunity for Social Welfare Nonprofit Organizations given by the Legal System; 4.2 The Interpretation of Immunity for Social Welfare Nonprofit Organizations given by the Supreme Court on the Case ADIN 2.028, regarding the Concept of Social Welfare; Conclusion; Bibliography.

\section{INTRODUÇÃO}

O presente trabalho tem por finalidade analisar a imunidade tributária das entidades beneficentes de assistência social às contribuições de seguridade social como direito e garantia fundamental, e especialmente, a 
significação da decisão do Supremo Tribunal Federal na Ação Direta de Inconstitucionalidade de número 2.028.

Neste julgado o Supremo Tribunal Federal, por seu órgão Pleno, referendou a medida liminar deferida, interpretando a Constituição Federal de 1988 e definido o conceito constitucional de Entidade Beneficente de Assistência Social e de assistência social.

O tema tem relevância prática, pois são estas entidades que proporcionam aos brasileiros a maior parte dos direitos sociais previstos no artigo $6^{\circ}$ da Constituição Federal de 1988 que deveriam ser alcançados pelo Estado, especialmente nas áreas de educação, saúde e assistência social.

Igualmente o tema tem relevância científica, pois esta decisão do Supremo Tribunal Federal é um marco em termos de intepretação constitucional, mas, não está sendo cumprida pelos destinatários da decisão da referida ação direta de inconstitucionalidade.

Para se tratar do tema principal, primeiramente aborda-se questões relativas aos direitos sociais previstos no artigo $6^{\circ}$ da Constituição Federal de 1988, sua eficácia, e a caracterização da imunidade tributária com direito e garantia fundamental na modalidade de direito de defesa, processo de criação de norma jurídica pelo legislador e pelo judiciário, e o teor da referida decisão.

Ao final apresentar-se-á a conclusão do Autor, sempre coerente às premissas adotadas.

\section{OS DIREITOS SOCIAIS PREVISTOS NO ARTIGO $6^{\circ}$ DA CONSTITUIÇÃO FEDERAL DE 1988}

A Constituição Federal de 1988 trouxe como inovação dentre os direitos e garantias fundamentais, os direitos sociais.

No artigo $6^{\circ}$ da Constituição Federal de 1988 encontram-se positivados direitos cujos titulares são, de regra, os brasileiros e estrangeiros residentes no país, salvo o direito à saúde, que por ser vinculado à vida e ínsito à dignidade humana é estendido aos estrangeiros não residentes.

Para melhor apreciação do tema, transcreve-se o referido artigo $6^{\circ}$ :

"Art. $6^{\circ}$ São direitos sociais a educação, a saúde, a alimentação, o trabalho,
a moradia, o lazer, a segurança, a previdência social, a proteção à
maternidade e à infância, a assistência aos desamparados, na forma
desta Constituição".

O rol dos direitos sociais de que trata este artigo estão especificados no texto constitucional mais adiante: especialmente no título VIII, "Da Ordem Social". Sintaticamente este título está dividido em Capítulos, dos quais destacam-se, os seguintes, I - Disposições Gerais, II - Da Seguridade Social, III - Da Educação, da Cultura e do Desporto, VI - Do Meio Ambiente, VII - Da Família, da Criança, do Adolescente, do Jovem e do Idoso, VIII - Dos Índios. 
Analisando-se o conteúdo dos direitos dos quais os brasileiros são titulares e o Estado destinatário, adotando-se aqui a distinção entre titulares e destinatários proposta por Ingo Wolfgang Sarlet ${ }^{2}$, a conclusão inarredável é que a efetivação destes direitos é uma tarefa enorme, quiçá impossível.

Considerando o conceito de mandamento de otimização Robert Alexy ${ }^{3}$ para diferenciação entre princípios e normas, mutatis mutandis, pode-se afirmar que as normas do artigo $6^{\circ}$ da Constituição Federal de 1988 devem ser realizadas na maior medida do possível, dentro das possibilidades jurídicas e fáticas existentes.

A objeção que se pode fazer é que os direitos sociais refletem o mínimo existencial e contra estes não se poderia invocar a reserva do possível no sentido de realizar estes direitos somente na medida do possível.

De qualquer forma, importa dizer que desde antes da Proclamação da República os serviços de saúde, educação e assistência social em seu sentido lato - assistência e prestação dos direitos sociais - eram prestados aos titulares pelas Santas Casas, Hospitais Comunitários e Congregacionais, Escolas Religiosas e Comunitárias, e entidades sem fins lucrativos. Isso é fato incontroverso no Brasil.

O Estado não tem estrutura para prestar estes direitos de forma direta. Se fossem cessadas as atividades dos estabelecimentos de saúde, a prestação de serviços educacionais e os programas de assistência social prestados por particulares, o sistema de assistência de direitos sociais entraria em colapso. Aliás, hoje com o auxílio das entidades privadas já está quase em colapso o sistema de saúde.

O único direito que se defende seja de impossível execução por particulares, dentre os previstos no artigo $6^{\circ}$, da Constituição Federal de 1988 , é o direito à segurança, cuja execução é privativa do Estado, nos termos do artigo da Constituição Federal de 1988.

Importante salientar que os direitos sociais elencados no corpo do artigo $6^{\circ}$ da Constituição Federal de 1988 tem seu sentido explicado no título VIII da Constituição, de forma que a educação, por exemplo, abrange a cultura e o desporto. Da mesma forma o meio ambiente, a proteção da família, do idoso e do índio são direitos que estão vinculados aos direitos sociais do artigo $6^{\circ}$, além da sobreposição com direitos do artigo $5^{\circ}$, pois dele decorrentes, a exemplo do direito à vida, que abrange, em tese, direito de alimentação, direito ao meio ambiente equilibrado, etc.

A importância de se ressaltar esta parceria que há entre o Estado e as entidades sem fins lucrativos para a prestação de serviços que atendem aos

\footnotetext{
2 SARLET, Ingo Wolfgang. A Eficácia dos Direitos Fundamentais: uma teoria geral dos direitos fundamentais na perspectiva constitucional. 11. ed., Porto Alegre: Livraria do Advogado Editora, 2012. p. 209.

${ }^{3}$ ALEXY, Robert. Teoria dos Direitos Fundamentais. [Tradução Virgílio Afonso da Silva, 5. ed., alemã]. 2. ed., $2^{\text {a }}$ Tiragem, São Paulo: Malheiros Editores, 2012, p. 90.
} 
direitos sociais do artigo $6^{\circ}$, da Constituição Federal de 1988 decorre do tema do presente estudo, que está relacionado à imunidade das entidades beneficentes que prestam estes serviços.

\title{
2. A IMUNIDADE DO PARÁGRAFO SÉTIMO DO ARTIGO 195, DA CONSTITUIÇÃO FEDERAL DE 1988
}

A imunidade tributária prevista no parágrafo sétimo do artigo 195, da Constituição Federal de 1988 se refere às contribuições de seguridade social.

Conforme se denota do expresso texto constitucional, trata-se de uma imunidade subjetiva e condicionada.

Eis o texto do parágrafo sétimo do artigo 195, da Constituição Federal de 1988:

\begin{abstract}
"Art. 195. A seguridade social será financiada por toda a sociedade, de forma direta e indireta, nos termos da lei, mediante recursos provenientes dos orçamentos da União, dos Estados, do Distrito Federal e dos Municípios, e das seguintes contribuições sociais:

$\S 7^{\circ}$ São isentas de contribuição para a seguridade social as entidades beneficentes de assistência social que atendam às exigências estabelecidas em lei."
\end{abstract}

Portanto, é de fácil percepção a ligação entre as atividades das entidades beneficentes de assistência social e a promoção dos direitos sociais.

A atuação destas entidades em atividades de promoção dos direitos sociais é requisito para a fruição da imunidade, além do atendimento às exigências previstas em lei.

Mesmo se tratando de um direito e garantia fundamental, e, portanto, norma de aplicabilidade imediata, a Jurisprudência do Supremo Tribunal Federal decidiu, no Mandado de Injunção que haveria necessidade de edição da lei referida para o gozo da imunidade. Certo é que esta decisão não está atualizada com o entendimento contemporâneo sobre integração legislativa de direitos fundamentais, eis que neste julgado o Supremo Tribunal Federal determinou a notificação do Congresso para declarar a mora legislativa e determinar a edição da lei necessária à fruição da referida imunidade.

As controvérsias a respeito da imunidade tratada são inúmeras, cumprido destacar as mais relevantes: a questão da qualidade da lei para tratar da imunidade, se complementar ou ordinária; os requisitos para o enquadramento na norma e fruição da imunidade; conceito de assistência social; conceito de entidade beneficente e entidade beneficente de assistência social para os fins do parágrafo sétimo do artigo 195, da Constituição Federal de 1988.

Antes de adentrar nas especificidades do julgamento da ADIN 2.028, cumpre abordar a questão da imunidade como direito e garantia fundamental. 


\section{IMUNIDADE COMO DIREITO E GARANTIA FUNDAMENTAL}

A imunidade tributária é um instituto brasileiro. Conforme já dito anteriormente, outros países optaram por tratar suas desonerações tributárias por meio de isenções, ou seja, fora do texto constitucional.

Filosoficamente, a imunidade em nada difere da isenção, pois se tratam de formas de desoneração de um setor da sociedade, que não é tributado em suas atividades. Tanto a imunidade quanto a isenção, bem como toda e qualquer proposição prescritiva, tem relação com valores da sociedade e com comportamentos que ora são incentivados, ora desestimulados.

Todavia, para o Direito há uma diferença abismal entre os institutos da imunidade e da isenção, que merece destaque, mesmo que resumido: a imunidade é norma de competência negativa, de intributabilidade. A Constituição Federal outorga competência para que os entes federativos instituam tributos. Ao mesmo tempo em que a competência é outorgada, são retirados expressamente da possibilidade de tributação pessoas e atividades. No caso em apreço, havendo norma imunizante não se pode falar de "favor fiscal", muito menos suprimir o alcance da norma de incompetência tributária, pois a imunidade das entidades beneficentes está vinculada à satisfação de direitos sociais.

Conforme lição de Paulo de Barros Carvalho ${ }^{4}$, imunidade é:

...classe finita e imediatamente determinável de normas jurídicas, contidas no texto da Constituição Federal, e que estabelecem, de modo expresso, a incompetência das pessoas jurídicas de direito constitucional interno para expedir regras instituidoras de tributos que alcancem situações específicas e suficientemente caracterizadas.

Por sua vez, a isenção traduz um favor fiscal, pois a isenção presume necessariamente uma relação jurídico-tributária pré-existente.

A diferença básica entre os institutos é que havendo imunidade não é possível sequer a edição de lei que preveja a ocorrência de relação jurídicotributária. Exemplificando, a prestação de serviço de saúde por uma entidade beneficente imune jamais poderá ser objeto de lançamento de imposto sobre serviços; ao contrário, a prestação de serviços de saúde por uma empresa de saúde será objeto de lançamento de imposto sobre serviços, o qual poderá deixar de ser cobrado ou pago, dependendo da técnica de isenção adotada e o elemento da regra-matriz de incidência tributária atacado pela norma isentiva.

Adotando-se a classificação entre direitos a prestações e direitos de defesa, tem-se que a imunidade é um direito e garantia fundamental, de defesa.

\footnotetext{
${ }^{4}$ CARVALHO, Paulo de Barros. Curso de Direito Tributário. 24. ed., São Paulo: Editora Saraiva, 2012. p. 236.
} 
A imunidade se enquadra perfeitamente no conceito de direito de defesa, conforme lição de Ingo Wolfgang Sarlet ${ }^{5}$ :

\begin{abstract}
“... Neste sentido, cumpre relembrar que os direitos fundamentais, em razão de sua multifuncionalidade, podem ser classificados basicamente, em dois grandes grupos, nomeadamente os direitos de defesa (que incluem o direito de liberdade, igualdade, as garantias, bem como parte dos direito sociais - no caso, as liberdade sociais - e políticos) e os direitos a prestações (integrados pelos direitos a prestações em sentido amplo, tais como os direitos à proteção e à participação na organização de procedimento, assim como pelos direitos a prestações em sentido estrito, representados pelos direitos sociais de natureza prestacional. Se os direitos de defesa, como dirigidos, em regra, a uma abstenção por parte do Estado, assumem habitualmente a feição de direitos subjetivos, inexistindo maior controvérsia em torno de sua aplicabilidade imediata e justiciabilidade, o mesmo não ocorre com os direitos a prestações. ..." (negrito não original)
\end{abstract}

O princípio da capacidade contributiva corrobora a assertiva de que a imunidade tributária das entidades beneficentes de assistência social é de um direito e garantia fundamental, pois essas entidades não têm "sobras" de valores a serem oferecidas à tributação, uma vez que eventual superávit é obrigatoriamente aplicado nas atividades.

É tão forte o entendimento da supremacia da imunidade e sua imbricação com os direitos fundamentais que há doutrina, embora minoritária, que a considere um princípio ${ }^{6}$. Aliás, no preâmbulo da Constituição Federal de 1988 consta expressamente como valores supremos de uma sociedade fraterna, o exercício dos direitos sociais.

Assim, a imunidade das entidades beneficentes de assistência social que está diretamente ligada à prestação dos direitos sociais é fundamental no estado brasileiro.

A implicação maior de se considerar a imunidade das entidades beneficentes de assistência social um direito e garantia fundamental, dentre outras, está em se considerar esta imunidade uma cláusula pétrea, nos termos do artigo, 60, § 4º, IV, da Constituição Federal de 1988.

\title{
4. INTEPRETAÇÃO DA IMUNIDADE DAS ENTIDADES BENEFICENTES DE ASSISTÊNCIA SOCIAL
}

A imunidade objeto deste trabalho é norma jurídica, regra, inserta no parágrafo sétimo do artigo 195, da Constituição Federal de 1988, e como toda norma jurídica texto e norma não se confundem.

\footnotetext{
${ }^{5}$ SARLET, Ingo Wolfgang. Obra citada, p. 260.

${ }^{6}$ PESTANA, Márcio. O Princípio da Imunidade Tributária. São Paulo: RT, 2001, p. 63.
} 
Defende-se aqui que norma jurídica é a construção que o intérprete faz do texto da lei. Neste sentido cita-se doutrina de Paulo de Barros Carvalho ${ }^{7}$ e Humberto Ávila ${ }^{8}$, cumprindo apresentar o conceito deste último sobre o ponto específico:

"Ocorre que a aplicação do Direito depende precisamente de processos discursivos e institucionais sem os quais ele não se torna realidade. A matéria bruta utilizada pelo intérprete - o texto normativo ou dispositivo - constitui uma mera possibilidade de Direito. A transformação dos textos normativos em normas jurídicas depende da construção de conteúdos de sentido pelo próprio intérprete. Esses conteúdos de sentido, em razão do dever de fundamentação, precisam ser compreendidos por aqueles que os manipulam, até mesmo como condição para que possam ser compreendidos pelos seus destinatários."

Considerando que a abordagem deste trabalho trata de apreciação de decisão judicial, cumpre trazer o entendimento do Professor Eros Roberto $\mathrm{Grau}^{9}$, que enfatiza ser a intepretação autêntica, feita pelo Juiz, aquela criadora de norma jurídica.

Esta intepretação, como bem salienta Juarez Freitas ${ }^{10}$, deve ser feita considerando-se o sistema jurídico como um todo coerente e sistemático, sob pena de se desintegrar ou hiperintegrar a norma, fugindo dos valores de segurança de justiça, insculpidos no preâmbulo da Constituição Federal de 1988.

Destaca-se da obra de Juarez Freitas o seguinte trecho:

"Por isso, não se deve descurar da elaboração de uma nova maneira de compreender o sistema jurídico, que ultrapasse, de um lado, os passivismos e os emotivismos e, de outro, que estimule, numa era de indeterminações exacerbadas, a vinculação do intérprete menos ao texto legislado fugaz e episódico, mais aos princípios e objetivos fundamentais do ordenamento, assim como destacado no capítulo antecedente. É dizer, de acordo com as diretrizes legítimas que devem ser comtempladas com primazia pelo positivador derradeiro - o intérprete, na sua interação prudente e comedida com o ordenamento e com as reivindicações do caso." $[\ldots]$

Pelo que se depreende, a norma jurídica em sentido estrito não se confunde com o texto da lei, pois o texto da lei é somente o ponto de partida para a criação da norma jurídica, especialmente aquela aplicável ao caso concreto.

\footnotetext{
${ }^{7}$ CARVALHO, Paulo de Barros. Obra citada, p. 188.

${ }^{8}$ ÁVILA, Humberto. Teoria dos Princípios da Definição à Aplicação dos Princípios Jurídicos. 4. ed., $3^{\mathrm{a}}$ tiragem, São Paulo: Malheiros Editores, p. 16.

${ }_{9}$ GRAU, Eros Roberto. Ensaio e Discurso sobre a Interpretação/aplicação do Direito. 3. ed., São Paulo: Malheiros Editores, 2005, p. 24 e 34.

${ }^{10}$ FREITAS, Juarez. A Interpretação Sistemática do Direito. 5. ed., São Paulo: Malheiros Editores, 2010, p. 66.
} 


\subsection{Intepretação da Imunidade das Entidades Beneficentes de Assistência Social às Contribuições de Seguridade Social dada pelo Legislador Infraconstitucional}

O legislador infraconstitucional, após a promulgação da Constituição Federal de 1988 sempre tratou a imunidade em questão como se mera isenção o fosse.

Esta afirmação é aferível pela forma como a imunidade do parágrafo sétimo do artigo 195, da Constituição Federal de 1988 foi regulamentada pelo legislador: 1) por lei ordinária ao invés de lei complementar e nestas leis regulamentadoras por se valer da expressão isenção; e 2) por leis editadas nos moldes do artigo 176 e seguintes do Código Tributário Nacional.

A propósito cumpre referir que desde 1988 esta imunidade foi tratada pelas Leis 8.212/91, 9.732/98 e 12.101/09, sempre sob a forma de isenção, inclusive nos regulamentos respectivos.

Em 1991, a Lei 8.212 regulamentou a imunidade em questão no seu artigo 55, que previa:

Art. 55. Fica isenta das contribuições de que tratam os arts. 22 e 23 desta Lei a entidade beneficente de assistência social que atenda aos seguintes requisitos cumulativamente:

I - seja reconhecida como de utilidade pública federal e estadual ou do Distrito Federal ou municipal;

II - seja portadora do Certificado ou do Registro de Entidade de Fins Filantrópicos, fornecido pelo Conselho Nacional de Serviço Social, renovado a cada três anos;

III - promova a assistência social beneficente, inclusive educacional ou de saúde, a menores, idosos, excepcionais ou pessoas carentes;

IV - não percebam seus diretores, conselheiros, sócios, instituidores ou benfeitores remuneração e não usufruam vantagens ou benefícios a qualquer título;

$\mathrm{V}$ - aplique integralmente o eventual resultado operacional na manutenção e desenvolvimento de seus objetivos institucionais, apresentando anualmente ao Conselho Nacional da Seguridade Social relatório circunstanciado de suas atividades.

$\S 1^{\circ}$ Ressalvados os direitos adquiridos, a isenção de que trata este artigo será requerida ao Instituto Nacional do Seguro Social (INSS), que terá o prazo de 30 (trinta) dias para despachar o pedido.

$\S 2^{\circ} \mathrm{A}$ isenção de que trata este artigo não abrange empresa ou entidade que, tendo personalidade jurídica própria, seja mantida por outra que esteja no exercício da isenção.

Por sua vez, para a obtenção do certificado de Entidade de Fins Filantrópicos, havia a necessidade de aplicação em gratuidade, de, pelo menos vinte por cento da receita operacional (Decreto 752/93) e, posteriormente, 
vinte por cento da receita bruta (Decreto 2.536/98) e que o valor das gratuidades fosse maior ou igual ao valor das contribuições não recolhidas.

Em 1998 foi publicada a Lei 9.732, que alterava o artigo 55 da Lei 8.212/91 e passou a exigir:

\begin{abstract}
"Art.55
III - promova, gratuitamente e em caráter exclusivo, a assistência social beneficente a pessoas carentes, em especial a crianças, adolescentes, idosos e portadores de deficiência;

$\S 3^{\circ}$ Para os fins deste artigo, entende-se por assistência social beneficente a prestação gratuita de benefícios e serviços a quem dela necessitar.

$\S 4^{\circ} \mathrm{O}$ Instituto Nacional do Seguro Social - INSS cancelará a isenção se verificado o descumprimento do disposto neste artigo.

$\S 5^{\circ}$ Considera-se também de assistência social beneficente, para os fins deste artigo, a oferta e a efetiva prestação de serviços de pelo menos sessenta por cento ao Sistema Único de Saúde, nos termos do regulamento."
\end{abstract}

Esta lei, em suma, retirou as atividades de educação do rol das atividades de assistência social passíveis de prestação pelas Entidades Beneficentes de Assistência Social para os fins do parágrafo sétimo do artigo 195, da Constituição Federal de 1988 e trouxe a obrigatoriedade de atendimento totalmente gratuito para enquadramento na norma imunizante, entre outras questões.

Todavia, como o objeto do presente estudo é o conceito de atividade de assistência social para os fins da imunidade das entidades beneficentes de assistência social previsto no parágrafo sétimo do artigo 195, da Constituição Federal de 1988, limita-se o estudo da decisão do Supremo Tribunal Federal a este ponto.

4.2 Intepretação da Imunidade das Entidades Beneficentes de Assistência Social às Contribuições de Seguridade Social dada pelo Supremo Tribunal Federal no Julgamento da ADIN 2.028 no que concerne ao Conceito de Assistência Social

Quando do ajuizamento da ADIN 2.028, foi concedida medida liminar pelo Presidente do Supremo Tribunal Federal em razão da ADIN ser ajuizada no período de recesso forense.

Várias foram as causas de pedir da ADIN 2.028, sendo uma delas adotada como razão para concessão do pedido liminar: a necessidade da imunidade ser tratada por lei complementar, por se tratar de uma limitação constitucional ao poder de tributar, nos termos do artigo 146, II, da Constituição Federal.

Finalizado o recesso, a medida liminar foi referendada pelo Plenário do Supremo Tribunal Federal, porém, por argumento diverso: inconstitucionalidade material dos dispositivos da Lei 9.732/98. 
A questão da inconstitucionalidade formal, por se tratar de regulamentação de limitação constitucional ao poder de tributar por lei ordinária, não foi apreciada expressamente por questões processuais. É que em se tratando a Lei 8.212 de lei ordinária, em se declarando a inconstitucionalidade formal da Lei 9.732/98 que a alterou, haveria contradição argumentativa, pois a ADIN não foi ajuizada contra a Lei 8.212/91. Portanto, este argumento foi deixado de lado.

Ao referendar a medida liminar na ADIN 2.028, o Supremo Tribunal Federal assim se pronunciou:

AÇÃO DIRETA DE INCONSTITUCIONALIDADE No 2028-5 DISTRITO FEDERAL (MEDIDA LIMINAR)

RELATOR: MIN. MOREIRA ALVES

REQUERENTE: CONFEDERAÇÃO NACIONAL DE SAÚDE - HOSPITAIS, ESTABELECIMENTOS E SERVIÇOS - CNS

ADVOGADOS: IVES GANDRA DA SILVA MARTINS E OUTROS

REQUERIDO: PRESIDENTE DA REPÚBLICA

REQUERIDO: CONGRESSO NACIONAL

EMENTA: Ação direta de inconstitucionalidade. Art. $1^{\circ}$, na parte em que alterou a redação do artigo 55, III, da Lei 8.212/91 e acrescentou-lhe os $\S \S 3^{\circ}, 4^{\circ}$ e $5^{\circ}$, e dos artigos $4^{\circ}, 5^{\circ}$ e $7^{\circ}$, todos da Lei 9.732 , de 11 de dezembro de 1998.

- Preliminar de mérito que se ultrapassa porque o conceito mais lato de assistência social - e que é admitido pela Constituição - é o que parece deva ser adotado para a caracterização da assistência prestada por entidades beneficentes, tendo em vista o cunho nitidamente social da Carta Magna.

- De há muito se firmou a jurisprudência desta Corte no sentido de que só é exigível lei complementar quando a Constituição expressamente a ela faz alusão com referência à determinada matéria, o que implica dizer que quando a Carta Magna alude genericamente a "lei" para estabelecer princípio de reserva legal, essa expressão compreende tanto a legislação ordinária, nas suas diferentes modalidades, quanto à legislação complementar.

- No caso, o artigo 195, $\S 7^{\circ}$, da Carta Magna, com relação a matéria específica (as exigências a que devem atender as entidades beneficentes de assistência social para gozarem da imunidade aí prevista), determina apenas que essas exigências sejam estabelecidas em lei. Portanto, em face da referida jurisprudência desta Corte, em lei ordinária.

- É certo, porém, que há forte corrente doutrinária que entende que, sendo a imunidade uma limitação constitucional ao poder de tributar, embora o $\S 7^{\circ}$ do artigo 195 só se refira à "lei" sem qualificá-la como complementar - e o mesmo ocorre quanto ao artigo 150, VI, "c", da Carta Magna -, essa expressão, ao invés de ser entendida como exceção ao princípio geral que se encontra no artigo 146, II ("Cabe à lei 
complementar; .... II - regular as limitações constitucionais ao poder de tributar"), deve ser interpretada em conjugação com esse princípio para se exigir lei complementar para o estabelecimento dos requisitos a ser observados pela entidades em causa.

- A essa fundamentação jurídica, em si mesma, não se pode negar relevância, embora, no caso, se acolhida, e, em conseqüência, suspensa provisoriamente a eficácia dos dispositivos impugnados, voltará a vigorar a redação originária do artigo 55 da Lei 8.212/91, que, também por ser lei ordinária, não poderia regular essa limitação constitucional ao poder de tributar, e que, apesar disso, não foi atacada, subsidiariamente, como inconstitucional nesta ação direta, o que levaria ao não-conhecimento desta para se possibilitar que outra pudesse ser proposta sem essa deficiência.

- Em se tratando, porém, de pedido de liminar, e sendo igualmente relevante a tese contrária - a de que, no que diz respeito a requisitos a ser observado por entidades para que possam gozar da imunidade, os dispositivos específicos, ao exigirem apenas lei, constituem exceção ao princípio geral -, não me parece que a primeira, no tocante à relevância, se sobreponha à segunda de tal modo que permita a concessão da liminar que não poderia dar-se por não ter sido atacado também o artigo 55 da Lei 8.212/91 que voltaria a vigorar integralmente em sua redação originária, deficiência essa da inicial que levaria, de pronto, ao não-conhecimento da presente ação direta. Entendo que, em casos como o presente, em que há, pelo menos num primeiro exame, equivalência de relevâncias, e em que não se alega contra os dispositivos impugnados apenas inconstitucionalidade formal, mas também inconstitucionalidade material, se deva, nessa fase da tramitação da ação, trancá-la com o seu não-conhecimento, questão cujo exame será remetido para o momento do julgamento final do feito.

- Embora relevante a tese de que, não obstante o $\S 7^{\circ}$ do artigo 195 só se refira a "lei", sendo a imunidade uma limitação constitucional ao poder de tributar, é de se exigir lei complementar para o estabelecimento dos requisitos a ser observados pelas entidades em causa, no caso, porém, dada a relevância das duas teses opostas, e sendo certo que, se concedida a liminar, revigorar-se-ia legislação ordinária anterior que não foi atacada, não deve ser concedida a liminar pleiteada.

- É relevante o fundamento da inconstitucionalidade material sustentada nos autos (o de que os dispositivos ora impugnados - o que não poderia ser feito sequer por lei complementar - estabeleceram requisitos que desvirtuam o próprio conceito constitucional de entidade beneficente de assistência social, bem como limitaram a própria extensão da imunidade). Existência, também, do "periculum in mora".

Referendou-se o despacho que concedeu a liminar para suspender a eficácia dos dispositivos impugnados nesta ação direta.

\section{ACÓRDÃO}

Vistos, relatados e discutidos estes autos, acordam os Ministros do Supremo Tribunal Federal, em Sessão Plenária, na conformidade da ata 
do julgamento e das notas taquigráficas, por unanimidade de votos, em referendar a concessão da medida liminar para suspender, até a decisão final da ação direta, a eficácia do art. $1^{\circ}$, na parte em que alterou a redação do art. 55, inciso III, da Lei no 8.212, de 24.07.1991, e acrescentou-lhe os $\S \S 3^{\circ}, 4^{\circ}$ e $5^{\circ}$, bem como dos arts. $4^{\circ}, 5^{\circ}$ e $7^{\circ}$, da Lei $n^{\circ}$ 9.732, de 11.12.1998.

Brasília, 11 de novembro de 1999.

CARLOS VELLOSO - PRESIDENTE

MOREIRA ALVES - RELATOR

Do acórdão se extrai a seguinte passagem:

“... Do exame sistemático da Constituição, verifica-se que a Seção relativa à Assistência Social não é exauriente do que se deve entender como Assistência Social, pois, além de não se referir a carentes em geral, mas apenas a família, crianças, adolescentes, velhos e portadores de deficiência se sequer exigir de todos estes que sejam carentes, preceitua, em seu artigo 203, que ela se fará independentemente de contribuição à seguridade social, a indicar que será gratuita..." [...]

“... Esse conceito mais lato de assistência social - e que é admitido pela Constituição - é o que parece deva ser adotado para a caracterização dessa assistência prestada por entidades beneficentes, tendo em vista o cunho nitidamente social de nossa Constituição. Aliás, esta Cote tem entendido que a entidade beneficente de assistência social, a que alude o $\S 7^{\circ}$ do artigo 195 da Constituição, abarca a entidade beneficente de assistência social educacional (assim, no ROMS 22.192, relator Ministro Celso de Mello, no ROMS 22.360, relator Ministro Ilmar Galvão, e, anteriormente, no $\mathrm{MI} 232$ de que fui relator, os dois primeiros relativos à Associação Paulista da Igreja Adventista do Sétimo Dia que presta assistência educacional, e o último com referência ao Centro de Cultura Prof. Luiz Freire).

Analisando a decisão do Supremo Tribunal Federal, percebe-se que está em harmonia com o entendimento ora defendido, de que as atividades de assistência social passíveis de serem realizadas e qualificadas para os fins do parágrafo sétimo do artigo 195, da Constituição Federal de 1988, são aquelas que se relacionam à prestação dos direitos sociais, embora não tenha sido julgado o mérito desta ADIN.

Porém, em se tratando de uma decisão judicial do Supremo Tribunal Federal, em ação direta de inconstitucionalidade, eficaz e válida, é norma jurídica que tem de ser respeitada, mesmo em se tratando de decisão liminar.

Infelizmente, o legislador inseriu em dispositivos de lei e decretos, textos dos quais se constroem normas exatamente iguais àquelas declaradas inconstitucionais pelo Supremo Tribunal Federal. 


\section{CONCLUSÃO}

A norma do parágrafo sétimo do artigo 195, da Constituição Federal de 1988 trata de uma imunidade subjetiva e condicionada ao cumprimento de requisitos.

Estes requisitos não podem distorcer o conceito de Entidade Beneficente de Assistência Social, cujo objeto de atuação não se restringe à assistência social stricto sensu prevista no artigo 203 da Constituição Federal de 1988, sob pena de se infringir a norma imunizante.

De outra banda, restou clara a vinculação da imunidade à prestação dos direitos sociais, sendo a decisão do Supremo Tribunal Federal uma proteção tanto à imunidade, quanto aos titulares dos direitos sociais, pois são as Entidades Beneficentes de Assistência Social que, em grande parte, prestam serviços vinculados aos direitos sociais, o que não poderiam fazer por absoluta inviabilidade econômica, caso a imunidade não fosse assegurada.

Negar a imunidade a entidades beneficentes que atuam visando proporcionar direitos relativos a saúde, alimentação, trabalho, moradia, lazer, previdência social, proteção à maternidade e à infância, a assistência aos desamparados, meio ambiente, educação, cultura, desporto é absolutamente inconstitucional.

Portanto, resta concluir pela inconstitucionalidade das restrições existentes na Lei 8.212 e 12.101, que limitam a qualificação de Entidade Beneficente de Assistência Social às entidades de educação formal, saúde e assistência social strito sensu.

\section{BIBLIOGRAFIA}

ALEXY, Robert. Teoria dos Direitos Fundamentais. [Tradução Virgílio Afonso da Silva 5. ed., alemã]. 2. ed., $2^{\mathrm{a}}$ Tiragem, São Paulo: Malheiros Editores, 2012.

ÁVILA, Humberto. Teoria dos Princípios da Definição à Aplicação dos Princípios Jurídicos. 4. ed., São Paulo: Malheiros, 2005.

CARVALHO, Paulo de Barros. Curso de Direito Tributário. 24. ed., São Paulo: Editora Saraiva, 2012.

CARVALHO, Paulo de Barros. Direito Tributário Linguagem e Método. 5. ed., São Paulo: Noeses, 2013.

FREITAS, Juarez. A Interpretação Sistemática do Direito. 5. ed., São Paulo: Malheiros Editores, 2010.

GRAU, Eros Roberto. Ensaio e Discurso sobre a Interpretação/aplicação do Direito. 3. ed., São Paulo: Malheiros Editores, 2005, p. 24 e 34.

GRAU, Eros Roberto. O Direito Posto e o Direito Pressuposto. São Paulo: Malheiros, 1996, p. 19.

PESTANA, Márcio. O Princípio da Imunidade Tributária. São Paulo: RT, 2001.

SARLET, Ingo Wolfgang. A Eficácia dos Direitos Fundamentais: uma teoria geral dos direitos fundamentais na perspectiva constitucional. 11. ed., Porto Alegre: Livraria do Advogado Editora, 2012. 